\title{
An Equity Framework for Family, Community, and School Partnerships
}

\section{Annela Teemant,}

Professor, Indiana University-Purdue University Indianapolis, ateemant@iupui.edu

Gina Borgioli Yoder

Clinical Associate Professor, Indiana University-Purdue University Indianapolis,

gbyoder@iupui.edu

Brandon J. Sherman

Project Manager, Indiana University-Purdue University Indianapolis, shermanb@iu.edu Cristina Santamaría Graff

Assistant Professor, Indiana University-Purdue University Indianapolis, santamac@iupui.edu

Correspondence concerning this article should be addressed to Annela Teemant, Indiana University-Purdue University Indianapolis, School of Education, 902 West New York Street, Education/Social Work, ES 3121, Indianapolis, IN 46202. Email: ateemant@iupui.edu $317-274-1228$

This is the author's manuscript of the article published in final edited form as:

Teemant, A., Yoder, G. B., Sherman, B. J., \& Graff, C. S. (2021). An equity framework for family, community, and school partnerships. Theory Into Practice, 60(1), 28-38. https://doi.org/10.1080/00405841.2020.1827905 


\begin{abstract}
Equity has often been identified as a foundational concept for truly inclusive and reciprocal partnerships among schools, families, and communities. Equity can be difficult for schools to achieve without cultivating new paradigms for interacting with historically marginalized students, families, and communities. In order to bridge the ideal of equity with radical, scalable, and sustainable institutional change, we developed an equity framework for cultivating mutual interdependence among families, communities, and schools in partnership. Rooted in sociocultural and critical theories, this framework builds upon the values of mutual respect, democratic participation, critical consciousness, and sustainability. These values then support cycles of collaborative action amongst stakeholders leveraging problem posing and community organizing to address inequities. In our article, we discuss the underlying theory supporting the framework and elaborate upon its implications for practice.
\end{abstract}

\title{
Keywords:
}

Family engagement in education; School partnerships; Equity; Historically marginalized populations; critical sociocultural perspectives 


\section{An Equity Framework for Family, Community, and School Partnerships}

Educational equity is a laudable goal. It is, however, also a "wicked problem" with causes and effects being unrelenting and difficult to untangle while solutions are ever evolving and never absolute (Rittel \& Webber, 1973). With such complexities, Weber and Khademian (2008) argue that wicked problems require a network of stakeholders to work as "collaborative capacity-builders" to generate results (p. 334). However, in today's educational milieu, the potential to address persistent inequities in meaningful ways remains fundamentally improbable. Nationally, educational equity has been framed for the last 2 decades in very narrow terms as the disaggregation of student outcomes on high stakes tests (Nichols \& Berliner, 2007). As a result, high stakes testing has placed responsibility for solutions to inequities squarely, and by and large solely, on the backs of educators. This has established a culture of fear among educators marked by punishments, incentives, teacher evaluation, school grading systems. In turn, this has set the stage for the reduction of teacher professionalism and judgment in the form of teaching to the test, scripted curricula, or grade-level fidelity to a lesson plan (Wills \& Sandholtz, 2009). Echoing Du Bois (1986), Paris and Alim (2014) warn that the achievement gap narrative has made students vulnerable to being seen "through a lens of contempt and pity" (p. 85). All the while, inequities persist between White students and historically marginalized student populations with cultural, linguistic, economic, and/or learning differences (Carter \& Welner, 2013). Internationally, equity is not as driven by high stakes testing yet similar outcome disparities exist (e.g. OECD, 2018). Dehumanizing school practices tied to race, immigrant status, or class are evident in many countries (e.g., Sime et al., 2020).

Figuratively, without interdependent partnerships with other stakeholders, educators are perched on an unstable stool with one leg. They are being asked to address equity issues that are complex and profound in scope without adequate access to and input from the multiple and 
varied stakeholders whose differing perspectives, values, and experiences matter most to students. This article will argue that educational equity requires students, families, community members and organizations, as well as school personnel to engage as agents of equity in local contexts. These agents of equity, as collaborative capacity builders, should be (a) equipped with new values-driven mindsets, (b) fully capable of problem posing and community organizing, and (c) committed to collective political action. Following our framing of equity, we will describe the assumptions and theories informing our framework for engaging in values-driven equity partnerships.

\section{Framing the Pursuit of Equity}

We begin with the premise that schooling should be socially just, equitable, and affirming for historically marginalized learners and their families. Osta and Perrow (2008) argue for 3 fundamental features of educational equity. First, student success or failure must not be determined by any a priori differences based on cultural, social, or economic factors. Second, equity requires disrupting bias and oppression found in school policies, practices, and learning environments. Third, equity must entail the cultivation of students' unique talents, abilities, and hybrid identities (see Wozolek; Brice-Heath \& Landay, this issue).

We define equity as differentiated support enabling all learners to achieve their potential in the face of diverse circumstances. In practical terms, this means going beyond school outcome measures to account for influencing factors inside and outside of school; that is, equity is not a student problem but a collective adult struggle against all forms of dehumanization that allow inequity to manifest because of race, language, culture, national origin, religion, sex, gender identity, (dis)abilities, or social class. The pursuit of equity demands cultural, historical, and political reflective inquiry and disruption of the status quo (Freire, 1994). 
As typical of wicked problems, Lee (2017) argues interconnected and complex layers of empirical research from "the biological, psychological and social sciences" (p. 105) now make clear that addressing inequities must be accompanied by valuing diversity, understanding learning and human plasticity, and the centrality of culture. She underscores the peril of failing to recognize "how perceptions of experience are deeply influenced by perceptions" stemming from differences (p. 93). Salazar (2013) shared how damaging school can be: "I abhorred being la morena, the dark-skinned girl. I came to associate whiteness with success and brownness with failure. I was overwhelmed with feelings of shame over the most essential elements of my humanness" (p. 121).

For students, equity is something seen, heard, felt, and experienced psychologically and through social interactions. In learning environments, research shows that "Perceptions matter. Feelings or emotions matter. Attachments matter. Mental representations of phenomenon in the world matter. Beliefs in self-efficacy and effort matter" (Lee, 2017, p. 105). Ultimately equity means removing "all barriers to learning...for all those experiencing disadvantage" (Ballard, 1999, p. 2). Therefore, we argue that any meaningful pursuit of educational equity must be seen as a collective call to acknowledge, unsettle, and dismantle the status quo of schoolingencompassing the policies, practices, programs, resources, and nature of interactions-as experienced by students and their families who are marginalized for any combination of differences. This means fairness and justice are at the heart of educational equity. As Barton and Tan (2020) assert, equity should not merely be inclusivity but result in the rightful presencelegitimate belonging — of marginalized students and families in our schools and communities. Further, equity means ensuring students access to the curriculum, opportunities for participation in the entire range of educational programs and activities offered, and equality in a variety of 
learner outcomes. When enacted fully, equity improves schooling and the human condition for all.

\section{Intersecting Theoretical Foundations for Practice}

Given our framing of equity, we have identified 3 theoretical perspectives as foundational to building the capacity among a network of stakeholders as agents of equity to engage in the collaborative work of addressing inequities. These theories highlight the importance of seeing equity (a) as a relational, inclusive, and values-driven change process; (b) as inherently grounded in community with all of its social, cultural, historical, and political realities; and (c) as requiring a systems thinking approach. We will briefly describe our rationale for situating our work in these theoretical perspectives in support of acknowledging, unsettling, and dismantling dehumanizing policies, practices, or conditions leading to inequities.

\section{Change Theory}

Agents of equity must first understand that education in all forms is fundamentally about change processes. While change can occur at the personal, social, or systems levels, it is always a result of influence and "influence is social" (Tharp, 2012, p. 6). Tharp articulated a theory of change called Delta Theory. He observed that real change is rare because psychosocial systems all tend toward inertia, stability, or the status quo. Tharp argued that "Influence and change operate primarily, indeed almost exclusively, within and through psychosocial systems - that is, affiliated persons organized into systems that share values, purpose, and activity" (p. 5). In other words, shared values, motives, perceptions, goals, and interpretations of the world (i.e., intersubjectivity) can only emerge when stakeholders—students, families, communities, and educators —work together collaboratively with a shared purpose: Ensuring educational equity.

From a theory of change perspective, the major obstacle in equity work is overcoming the segregation, isolation, and fundamental lack of social interaction among educators themselves 
and with stakeholders in particular. Tharp et al. (2000) observed that social relationships are patterned and organized "primarily along social class and its components_-income, education, race, culture, and language" (p. 53). To varying degrees, the social relationships in classrooms and schools mirror our social relationships out of school. Because educators do not always live and teach in the same communities and people typically only engage with people they socialize with, opportunities for collaboration are rare.

Greater educational equity, therefore, cannot emerge from stakeholders merely being in physical proximity (i.e., propinquity) to each other in school settings. In practice, stakeholders must intentionally decide to work together on a common cause. A pivotal outcome of such collaboration is the development of intersubjectivity: That is, the creation of shared values, perceptions, and interpretations of the world (Tharp et al., 2000). Enfield and Sidnell (n.d.) explain that what makes such shared values powerful is understanding that "intersubjectivity is more than merely heeding others, or even being aware of what others see, want, or know" (p. 2). They see intersubjectivity as joint activity plus being "socially accountable for their participation" as well (p. 2).

We cannot have dynamic relational understandings, develop shared values, or influence change if we do not invite students, families, and community representatives of underserved populations to engage with educators in substantive dialogue. This type of dialogic work means changing the very "nature of the relationships, or patterns of relating" in schools (Pounder, 1998, p. 29). As Tharp (2012) acknowledged, "Shifts in culture involve shifts in power and privilege” (p. 81). Fundamentally, values guide our actions. Therefore, in practice educators must commit to changing the relational dynamics among stakeholders to prioritize new ways of collaborating as valued and necessary. 


\section{Critical Social Theory}

Dialogue is how agents of equity develop shared values, perceptions, and interpretations of the world. Freire (1994) described dialogue as needing to encompass both reflection and action (i.e., praxis) to be transformative. Freire's dialogic process of naming, reflecting, and taking action means taking a Critical Stance, defined as "consciously engaging in interrogating conventional wisdom and practices; reflecting upon ramifications of such practices; and actively seeking to transform inequities (Teemant et al., 2014, p. 14).

Naming inequities requires honest, courageous, and uncomfortable conversations. Without equivocation, every educator should have at the core of who they are an unwavering commitment to the overall well-being and academic success of historically marginalized students. However, as Salazar (2013) observed, "deficit notions of Communities of Color have fueled intolerance, bigotry and assimilation throughout the history of US public education" (p. 122). Alim and Paris (2017) argue for the need to reframe the White, middle class norm, where educators ask, "How can 'we' get 'these' working-class kids of color to speak/write/be more like middle-class White ones" (p. 3). Naming the psychological and social burdens placed upon historically marginalized students is a necessary step in transforming persistent inequities and reaching "parity of participation" in schooling (Fraser, 2009, p. 16).

Reflection allows us to understand education itself and equity in particular as overtly political undertakings. Critical perspectives (e.g., Alim \& Paris, 2017; Freire; 1994) point to the importance of interrogating the social, cultural, linguistic, historical, economic, institutional barriers and realities of local communities. Why? Because such realities either limit or expand the potential of groups of students, their identity development, agency, and ability to counter inequitable power relations. Reimaged schools, therefore, should be "sites where diverse, 
heterogeneous practices are not only valued but sustained" and the "object of critique" is not students themselves but “oppressive systems" (Alim \& Paris, 2017, p. 3).

What humanizing actions, then, would make schooling more equitable places for historically marginalized students and families? It means naming the inequities that are uncovered in a dialogic change process involving all stakeholders. It requires being open and compassionate towards others when seeing the world from multiple and more inclusive points of view (Dalai Lama, Tutu, \& Abrams, 2016). It means listening to understand those who struggle or feel invalidated, invisible, or oppressed for being labelled different (DuBois, 1986; Paris \& Alim, 2014; Salazar, 2013). Finally, it means taking action in solidarity with those being excluded to transform processes and outcomes of schooling towards equity.

Critical social theories teach us that in practice engaging stakeholders in reciprocal, dialogic, democratic, and humanizing discussion, problem posing, and community organizing is an explicitly political process. Naming, reflecting, and taking action to free schools from their inequitable structures and practices requires dialogue inclusive of previously excluded students, families, and communities. Freire (1994) argued passionately about this as a "dialogical theory of action" (p. 148) to transform the world. He asserted, "No matter where the oppressed are found, the act of love is commitment to their cause - the cause of liberation. And this commitment, because it is loving, is dialogic" (p. 70).

\section{Systems Thinking}

As a wicked problem, the scope and complexities of educational inequities require systems thinking or as Pounder (1998) described it, a change to the "basic nature of the system of organizing itself" (p. 34). Pounder viewed persistence and change as "two sides of the same coin" (p. 32). She explained, "Attending to only half of the dialectic leads to either/or thinking. 
That is, either change or persistence" (p. 33). In practice, agents of equity make use of systems thinking to unpack the status quo and envision change.

The book Schools That Learn (Senge et al., 2012) presents a useful approach to studying system structures and behaviors. Senge et al. describe 5 disciplines, with concrete practices and protocols, for leading systems change in how people think and work together. Systems thinking entails generating collective aspirations in a way that coheres with Delta Theory, through, for example, shared vision (i.e., intersubjectivity) and team learning (i.e., collaborative joint activity). In line with critical perspectives, Senge et al. argue leaders need reflective thinking skills to surface and challenge stakeholders' implicit and un-scrutinized beliefs, assumptions, and sources of thinking (i.e., mental models). Similar to Freire's (1994) dialogic action, Senge et al. argue changing mental models requires, "reflection (slowing down our thinking processes to become aware of how we form our mental models) and inquiry (holding conversations where we openly share views and develop knowledge about each other's assumptions)" (pp. 100-101). To such dialogic practices, students, families, community representatives, and educators each contribute insights, experiences, expertise, and even skills in community organizing that make a difference for addressing inequities. Personal mastery, or individual aspirations, remains important for any participant in a change process. However, systems thinking, in contrast to mechanistic thinking, is about collectively recognizing and managing complexity: This means seeing inequity as part of a whole (e.g., broader society) and understanding the root causes of its complexities through examining relationships, interdependencies, patterns, structures, generalities, and feedback loops.

\section{Equity Framework for Reciprocal Partnerships}

Informed by Delta Theory, critical perspectives, and systems thinking, we developed an overarching framework for engaging in equity partnerships (Figure 1). Stakeholders are framed 
as agents of equity. As they confront the wicked complexities of real-world inequities, this framework can serve as a compass for both navigating processes and articulating a shared vision. Their common cause is to tackle systemic inequities by joining with those who have been excluded, marginalized, or oppressed by schooling. Through authentic, meaningful, ongoing, and reciprocal learning and thinking about inequities (i.e., problem posing), stakeholders strive to courageously take political action against oppressive and inequitable systems, structures, and behaviors (community organizing). Because change processes are social, we argue that change will only occur to the degree that shared values are generated; therefore, this equity framework is values-based, serving as a foundation for bridging differences.

\section{Insert Figure 1 here}

\section{Guiding Values}

In this section, the guiding values of mutual respect, democratic participation, critical consciousness, and sustainability are briefly defined. These values represent a starting point for equity work. As partnerships mature, trust deepens, and shared perspectives take shape, partnerships may develop additional unifying, place-based values.

\section{Mutual Respect}

Partnerships must be built on a foundation of mutual and reciprocal respect. Valuing multiple perspectives, particularly those of marginalized communities, is a hallmark of respect. This requires thoughtful and ongoing cultivation of a safe space for differing perspectives to be shared. Stakeholders must also come to recognize the legitimacy of differences among each other. Respect matures through dialogue, shared goals and understandings, and trust based in experience. As part of a respectful process, stakeholders who have been positioned by society as having legitimacy and power in schools need to reflect upon and grapple with their own privilege, power, and biases. Further, stakeholders must recognize that earned trust is a powerful 
but fragile aspect of partnerships, something that takes time to establish and requires ongoing reinforcement to thrive.

\section{Democratic Participation}

Democracy is messy, and democratic participation in schooling is no different (Meshulam \& Apple, 2018). Ideally, a reciprocal school partnership would be an organized effort to ensure power sharing with a broad span of stakeholders, 2-way communication, and transparency in organization, governance, and decision-making. Such democratic processes draw value from a commitment to ensuring each individual and group authentically has voice, is included, heard, represented accurately, well-informed, and part of decision-making (e.g., Fraser, 2008; Swartz, 2018). Democratic processes also demand robust and proactive responsiveness to structural barriers, school complexities, and efforts by existing hierarchies of power to limit student, family, and community participation.

\section{Critical Consciousness}

Critical consciousness asks individuals and groups to become aware that the world is structured to privilege some peoples while marginalizing others in ways that diminish, harm, or limit their personal sovereignty (Freire, 1994). Critical consciousness argues against the narrative that individuals alone are responsible for societal inequities. In small and large ways, one's choices and opportunities are constrained by circumstances within and also beyond one's control. As stakeholders engage in authentic discussions, they begin by acknowledging dominance: naming and identifying instances of privilege or marginalization that regularly produce advantages or disadvantages based on differences, such as race, language, class, culture, gender, religion, sexuality, etc. Reflecting upon dominance allows stakeholders to see such instances as part of a larger system of interconnected and interdependent processes, 
structures, or interactions that result in inequities. Using mutual respect and democratic participation, stakeholders develop shared understanding about the challenges leading to inequities and consciously explore dismantling dominance. Such action restores those marginalized to a sense of control of their life trajectories, improving schooling and the world outside the schoolhouse. Critical consciousness allows change at all levels: personal, social, and systems change.

\section{Sustainability}

By definition, complex problems need sustained effort over time to understand, unpack, and resolve. For this reason, equity projects must be self-sustaining. Sustainability, as a value, is characterized by patterns and structures of participation that are stable and enduring, transcending individuals. Sustainability is bolstered by an ongoing yet evolving shared vision that arises from authentic collaboration. Accountability to commitments becomes an iterative process of setting goals, identifying benchmarks, and celebrating outcomes. Further, sustainability depends on the ongoing development of stakeholder capacities to communicate, organize, and lead change processes. While fundraising may be a useful skill, equity-oriented partnerships emphasize dialogue, reflection, and meaningful action for humanizing schooling for marginalized populations. Stakeholders who are positioned to learn, do, and lead collaborative activity pass their knowledge and skills to newcomers, allowing equity pursuits to be ongoing and evolving.

In summary, a values-driven framework operates in practice as an ongoing dialogic relationship among educators and marginalized populations to name, reflect, and take action through negotiated and shared purpose, values, and goals to critique oppressive systems. This includes critiquing the relationships, hierarchies, structures, or patterns that support them. As 
such, a values-based equity framework is realized through the relationships among stakeholders engaged in authentic dialogue and collaboration for equity's sake. The framework values function synergistically. There is no one-to-one alignment between a value and an action in practice. Unlike actions, values cannot be checked off a "to do" list. Rather, actions emerge in local settings as a result of values-driven interactions where shared interpretations of issues are forged. Often in the name of school-community partnerships, educators generate "action items" to be completed (i.e., become more welcoming, generate multilingual materials for families, or hold a home literacy workshop for families). Yet without the underlying relationships of trust or shared values, such actions fail to critique or dismantle how school systems explicitly or implicitly marginalize students and families. Therefore, in practice, we argue that shared values must come first. Only then can capacities and actions develop to meet local challenges.

\section{Capacities}

Equipped with a values-driven mindset, agents of equity employ 2 key capacities: Problem Posing and Community Organizing. These capacities are not discrete but support each other as cycles of reflection and action in the real world. As shared understanding deepen, so too does capacity for influence and transformation. In turn, through feedback and reflection, action increases understanding.

\section{Problem Posing: Reading the World}

Problem posing represents a dialogic and relational approach to understanding the world and one's circumstances in it. Freire and Macedo (2005) described problem posing as learning to "read the world" or "perceiving the relationship between text and context" (p. 29). In collaboration and solidarity, agents of equity pursue authentic and meaningful conversations, rich with reflection and analysis. Reflection supports participants in uncovering new or more expansive understandings about their needs, goals, assumptions, beliefs, practices, and 
circumstances. Through analysis, stakeholders gather, interpret, and synthesize a variety of data to identify problems and understand their root causes in context. Problem posing is reciprocal learning and thinking: There are no "sanctioned" answers, perspectives, or ways of being. Differences are considered legitimate, understandings are co-constructed, and self-determination required. Freire (1994) argued that the outcome of problem posing is always "directed toward humanization" (p. 66).

\section{Community Organizing: Writing the World}

With shared motives, values, and vision in place, stakeholders can act to transform their circumstances through community organizing. This capacity encompasses the ability to act in concert through collaboration and informed advocacy. Quality collaboration is marked by shared ownership and responsibility. Agents of equity, therefore, must respectfully balance the needs and goals of multiple stakeholders to reach a mutually agreed upon course of action that accounts for the positions of all involved. Inclusive transformation also includes informed advocacy, in which stakeholders act as channels of communication to and from the broader community, building unity around a common cause.

\section{Conclusion}

After more than 20 years of compliance-oriented and high stakes testing approaches to equity, it is time to be inspired by a better and higher cause. We offer as such a cause our collective effort to transform, and thus humanize, schooling and society into more equitable places. The framework presented is grounded in theories of change, power, and systems. In practice, such work must begin with agents of equity engaging in authentic dialogue resulting in shared values, reciprocal learning, and shared vision, language, and commitment to collective and political action for equity's sake. Some may argue that such a cause is beyond the scope of schooling. We counter that such a cause is the very purpose of schooling in a democracy: 
Empower learners and citizens to transform the world toward greater justice. Incremental, individual, isolated change is not enough. Educators must have the moral courage to do the difficult work of humanizing schooling in collaboration with stakeholders. Values-based reciprocal partnerships are an essential means for engaging with equity with historically marginalized students, families, and communities.

\section{Acknowledgements}

This work was supported by the United States Department of Education under the Office of English Language Acquisition's National Professional Development Grant (T365Z170226). The U.S. Department of Education had no role in the design, execution, analysis, or preparation of this manuscript for publication. The contents, findings, and opinions presented are solely those of the authors.

\section{Declaration of Interest Statement}

The authors have no financial or business conflicts of interest associated with this work.

\section{References}

Alim, H. S., \& Paris, D. (2017). What is culturally sustaining pedagogy and why does it matter? In D. Paris, \& H. S. Alim (Eds.), Culturally sustaining pedagogies: Teaching and learning for justice in a changing world (pp. 1-21). Teachers College Press.

Ballard, K. (Ed.) (1999). Inclusive education: International voices on disability and justice. Falmer Press.

Barton, A. C., \& Tan, E. (2020). Beyond equity as inclusion: A framework of "rightful presence" for guiding justice-oriented studies in teaching and learning. Educational Researcher. Advanced online publication. https://doiorg.proxy.ulib.uits.iu.edu/10.3102/0013189X20927363 
Carter, P. L., \& Welner, K. G. (2013). Closing the opportunity gap: What America must do to give every child an even chance. Oxford University Press.

Dalai Lama, Tutu, D., \& Abrams, D. (2016). The book of joy: Lasting happiness in a changing world. Avery.

Du Bois, W. E. B. (1986). Writings: The suppression of the African slave-trade/The souls of black folk/Dusk of dawn/Essays and articles. Library of America.

Enfield, N. J. \& Sidnell, J. (n.d.). Intersubjectivity is activity plus accountability. Academia. https://www.academia.edu/39576706/Intersubjectivity_is_activity_plus_accountability

Freire, P. (1994). Pedagogy of the oppressed. Continuum.

Freire, P., \& Macedo, D. (2005). Literacy: Reading the word and the world. Routledge.

Fraser, N. (2009). Scales of justice: Reimagining political space in a globalizing world. Columbia University Press.

Lee, C. D. (2017). Integrating research on how people learn and learning across settings as a window of opportunities to address inequities in educational processes and outcomes. Review of Research in Education, 41, 88-111. https://doi.org/10.3102/0091732x16689046

Meshulam, A., \& Apple, M. W. (2018). The contradictions of a critically democratic school. In M. W. Apple with L. A. Gandin, S. Liu, A. Meshulam, \& E. Schirmer, The struggle for democracy in education: Lessons from social realities (pp. 20-40). Routledge. https://doi.org/10.4324/9781315194684-2

Nichols, S. L., \& Berliner, D. C. (2007). Collateral damage: How high-stakes testing corrupts America's schools. Harvard University Press.

OECD. (2018). Equity in education: Breaking down barriers to social mobility. PISA, OECD 
Publishing. https://doi.org/10.1787/9789264073234-en

Osta, K., \& Perrow, K. (2008). Coaching for educational equity: The BayCES coaching framework. Bay Area Coalition for Equitable Schools. https://nationalequityproject.org/wp-content/uploads/2010/10/CFEE08.pdf

Paris, D., \& Alim, H.S. (2014). What are we seeking to sustain through culturally sustaining pedagogy? A loving critique forward. Harvard Educational Review, 84, 85-100. https://doi.org/10.17763/haer.84.1.9821873k2ht16m77

Pounder, D., G. (1998). Teacher teams: Redesigning teachers' work for collaboration. In D. G. Pounder (Ed.), Restructuring schools for collaboration: Promises and pitfalls (pp. 6588). State of New York Press.

Rittel, H. W., \& Webber, M. M. (1973). Dilemmas in a general theory of planning. Policy Sciences, 4, 155-169.

Salazar, M. (2013). A humanizing pedagogy: Reinventing the principles and practices of education as a journey toward liberation. Review of Research in Education, 37, 121-148. https://doi.org/10.3102/0091732x12464032

Senge, P., Cambron-McCabe, N., Lucas, T., Smith, B., Dutton, J., \& Kleiner, A. (2012). Schools that learn: A fifth discipline fieldbook for educators, parents, and everyone who cares about education. Crown Business.

Sime, D., Moskal, M., \& Tyrrell, N. (2020). Going back, staying put, moving on: Brexit and the future imaginaries of the 1.5-generation of EU migrants in Britain. Central and East European Migration Review 9, 85-100. https://doi.org/10.17467/ceemr.2020.03

Swartz, E. E. (2018). Locating democracy and Benjamin Banneker: Theory and practice. In J. E. King \& E. E. Swartz (Eds), Heritage knowledge in the curriculum: Retrieving an African 
espisteme (pp. 25-55). Routledge. https://doi.org/10.4324/9781351213233-2

Teemant, A., Leland, C., \& Berghoff, B. (2014, April). Development and validation of a measure of Critical Stance for instructional coaching. Teaching and Teacher Education, 39, 136-147. Retrieved from http://dx.doi.org/10.1016/j.tate.2013.11.008.

Tharp. R. G. (2012). Delta theory and psychosocial systems: The practice of influence and change. Cambridge University Press. https://doi.org/10.1017/CBO9781139056199

Tharp, R. G., Estrada, P., Dalton, S. S., \& Yamauchi, L. (2000). Teaching transformed: Achieving excellence, fairness, inclusion, and harmony. Westview Press. https://doi.org/10.4324/9780429496943

Weber, E. P., \& Khademian, A. M. (2008). Wicked problems, knowledge challenges, and collaborative capacity builders in network settings. Public Administration Review, 68(2), 334-349. https://doi.org/10.1109/emr.2010.5559144

Wills, J.S., \& Sandholtz, J.H. (2009). Constrained professionalism: Dilemmas of teaching in the face of test-based accountability. Teachers College Record, 111, 106-114. 
Figure 1: Equity framework for reciprocal family, community, \& school partnerships.

\section{EQUITY FRAMEWORK FOR REGIPROCAL FAMILY, COMMUUITY, 6 SGHOOL PARTIERSHIIPS}

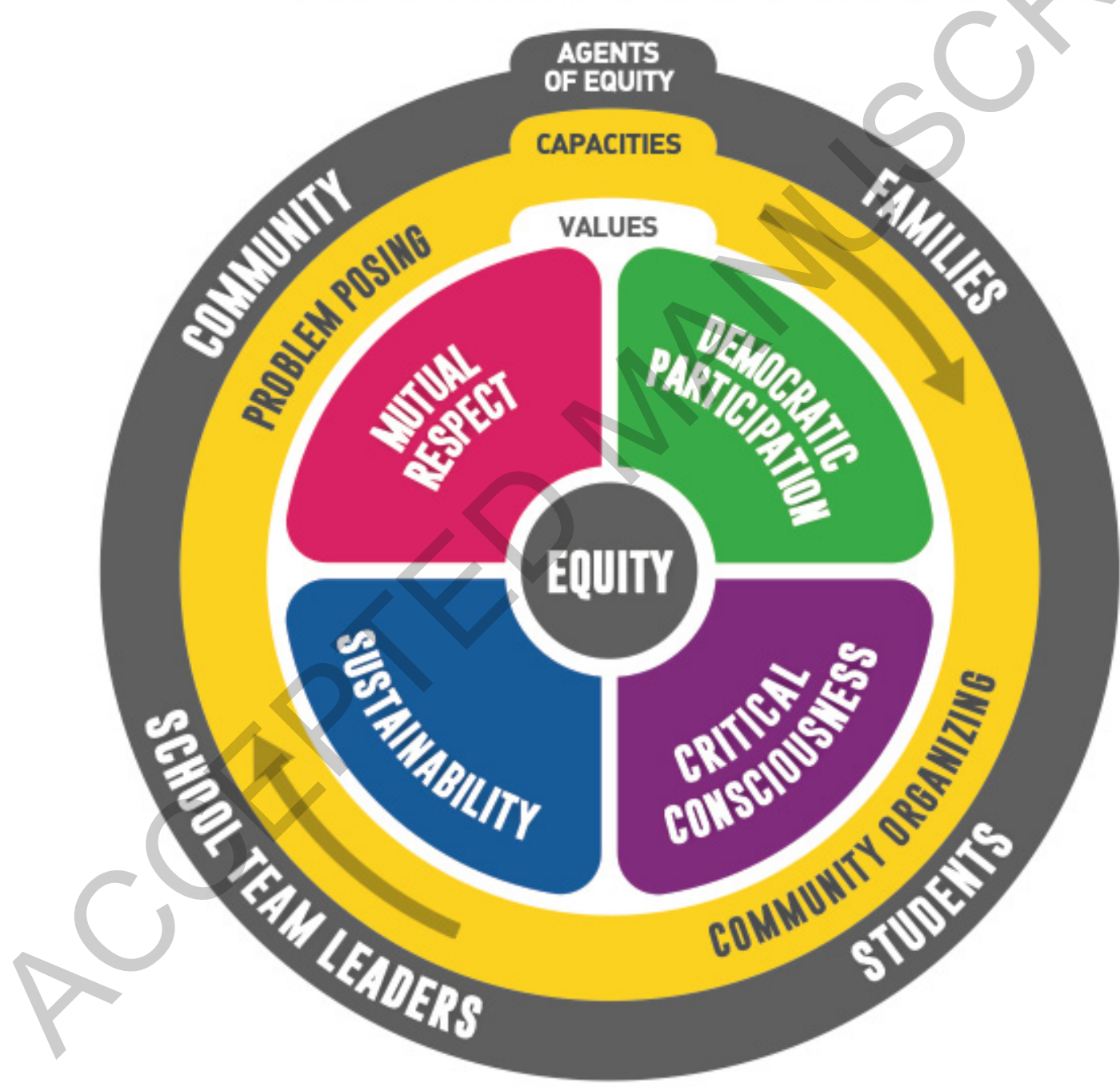

Additional Resources for Classroom Use 


\section{The Great Lakes Equity Center website: https://greatlakesequity.org/}

Funded by the U.S. Department of Education, this regional center, located at Indiana University Purdue University Indianapolis, serves a 13-state region free of charge in addressing equitydriven system change, professional learning, and collaborative inquiry. The website offers learning experiences and a plethora of resources for addressing equity, such as newsletters, briefs, podcasts, vodcasts, presentations, equity tools, digests, and webinars.

2. Moule, J. (2012). Cultural competence: A primer for educators. Wadsworth Cengage

\section{Learning.}

This book provides a comprehensive overview of how to become culturally competent, with applications to classroom teaching and in teaching marginalized student groups. It is especially helpful for White and/or middle-class educators learning about racism, prejudice, microaggressions, privilege, and racial consciousness among Whites.

\section{Larson, J. (2014). Radical equality in education: Starting over in US Schooling.}

\section{Routledge.}

This 92-page book outlines what educators need to do now to reimagine schooling. Using a humanist and democratic view of learning and equality, Larson presents bold ideas that require collective political action to improve schooling for all students. 